Original Research Paper

\title{
Using a Modified Technology Acceptance Model to Evaluate Designing Eight Queens Chess Puzzle Game
}

\author{
Hussain Mohammad Abu-Dalbouh \\ Department of Computer Sciences, College of Sciences and Arts at Unaizah, \\ Qassim University, Al-Qassim, Kingdom of Saudi Arabia
}

Article history
Received: 19-10-2015
Revised: 03-05-2016
Accepted: 16-05-2016

Email: hussainmdalbouh@yahoo.com

\begin{abstract}
In the game of chess, the queen can attack any piece that lies on the same row, on the same column, or along a diagonal. The eight-queens is a classic logic puzzle. The task is to place eight queens on a chessboard in such a fashion that no queen can attack any other queen. The eight-queen puzzle is often used to illustrate problem-solving or backtracking techniques. Consequently, in this study Technology Acceptance Model has designed to investigate the user acceptance of designing Eight Queens Chess Puzzle Game. The purpose of this study is to design a quantitative approach based on the technology acceptance model questionnaire as its primary research methodology. It utilized a quantitative approach based a Technology Acceptance Model (TAM) to evaluate the designing Eight Queens Chess Puzzle Game from $1 \times 1$ to $25 \times 25$ levels. The related constructs for evaluation are: Perceived of Usefulness, Perceived Ease of Use, User Satisfaction and Attribute of Usability. All these constructs are modified to suit the context of the study. Moreover, this study outlines the details of each construct and its relevance toward the research issue. The outcome of the study represents series of approaches that will apply for checking the advantages of collecting all levels in a single game with series of episodes and how well it achieves the aims and objectives of the design.
\end{abstract}

Keywords: Puzzle Game, Designing, Methodology, TAM, Queens

\section{Introduction}

Artificial Intelligence researchers have for decades worked on building game playing systems capable of matching wits with the strongest humans in the world. The success of such systems has largely been because of improved search algorithms and years of relentless knowledge engineering effort on behalf of the program developers, manually adding game specific knowledge to their programs. One of the challenges of designing game for enhancing creativity, involving problem solving techniques and improving decision-making and thinking strategies. In addition, displaying all solutions while playing. The paper introduces a proposed eight queens chess puzzle game from $1 \times 1$ to $25 \times 25$ levels system and designs the Technology Acceptance Model (TAM) for its validation.

Effective evaluation of the proposed eight queens system by incorporating several levels, from $1 \times 1$ to $25 \times 25$, is necessary in order to ensure the proposed eight queens chess puzzle game from $1 \times 1$ to $25 \times 25$ levels systems adequately meet the requirements and information processing needs of the players. We design a Technology Acceptance Model to investigate user acceptance of eight queens chess puzzle game system. It proposes a research methodology that being employed to understand the objectives and requirements, design, develop and finally, validate the eight queens chess puzzle game system.

Research methodology is defined as procedures, ways, methods and techniques that are employed to capture and gather all the required information for the purpose of the research issue. Methodology refers to that branch of philosophy that analyzes the principles and procedures of an inquiry in a particular discipline. It is generally a guideline for solving a problem that outlines specific components, example: Phases, tasks, methods, techniques, tools and outputs. There are various methods that can be employed in gathering information from different sources such as sampling, site visits and observation of the study environment, questionnaires, interviews, prototyping and joint requirement planning. These strategies would be applied so as to validate and refine the projected hypothesis and arranged in line with structure of study. 


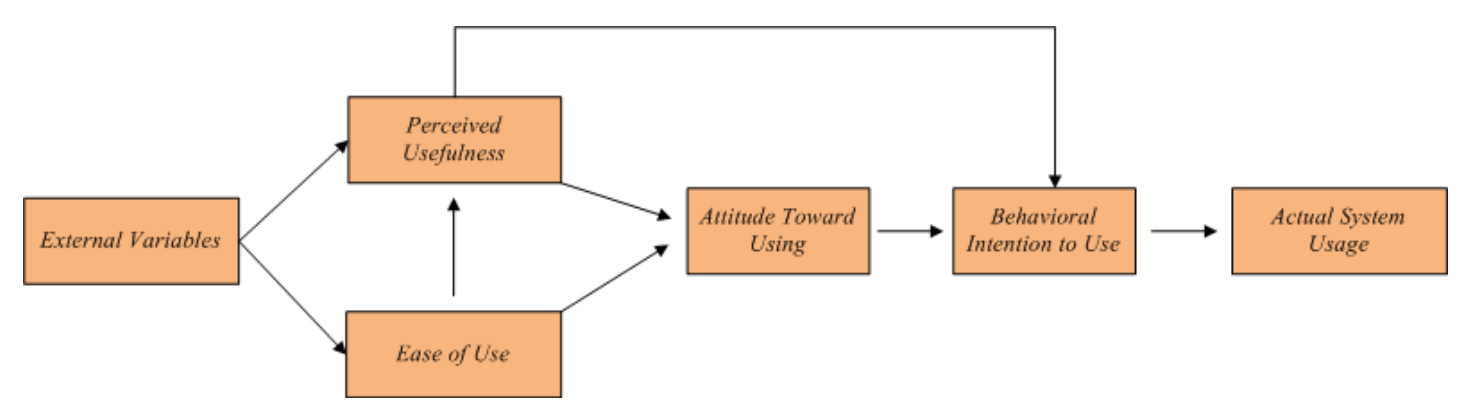

Fig. 1. Original Technology Acceptance Model (TAM)

Table 1. Comparison between qualitative and quantitative research

\begin{tabular}{ll}
\hline Qualitative & Quantitative \\
\hline What is X & How many X \\
Inductive process & Deductive process \\
Sample is selective (non-random) & Sampling is random \\
Researcher looks for patterns, themes and concepts & Concepts and hypothesis are chosen before the research begins \\
$\begin{array}{l}\text { Researcher develop a theory or compares patterns with } \\
\text { other theories }\end{array}$ & Researcher use instrument to measure the variables in the study \\
\hline
\end{tabular}

Thus, the study is organized specially to mirror the projected analysis methodology that may be applied to deal with the projected analysis issue. Debates encompassing the sector of analysis reveal two main principal analysis categories: Quantitative and qualitative. It's necessary to notice that quantitative analysis has been related to the positivist stance whereas qualitative analysis with the informative stance (Creswell, 2011). However, qualitative and quantitative must not be thought-about similar to instructive and positivist views severally. Additionally, the chance of qualitative and quantitative analysis to be either instructive, positivist, or important are planned. Qualitative analysis may be a sort of analysis that produces findings not came across by means that of applied math procedures or alternative means that of quantification and also the purpose behind the analysis is that the understanding of human expertise so as to reveal each the processes by which individuals construct that means regarding their worlds and to report what those meanings square measure. A qualitative analysis is taken into account to be associate degree investigation method that explains social development through constructing, comparing, replicating, categorizing and classifying the item of the study. In different words, qualitative analysis thinks about with words instead of numbers (i.e., in knowledge that's not quantifiable). On the opposite hand, quantitative analysis is analysis that depends on developing metrics (numbers) which will be accustomed describe the phenomena (objects and relationships) underneath study. It's a deductive method (i.e., logic supported rules, models and laws) consisting of measure and analyzing the link between variables. This method reveals however usually or what number folks act during a specific manner however it fails to answer the question of "why". Table 1 shows the comparison between qualitative and quantitative analysis.

The TAM would be valuable and useful for explaining or predicting user acceptance of new technology or system, particularly among students and executives in a university or business organization context, health care works and many fields as we can call all of them end users. The aims of this study is to design a quantitative approach based on the technology acceptance model questionnaire as its primary research methodology.

TAM starts by proposing external variables as the basis for tracing the impact of external factors on two main internal beliefs, which are perceived usefulness and perceived ease of use, while perceived ease of use also affects perceived usefulness over and above external variables. These two beliefs both influence user's attitude toward using Information System (IS). Attitude toward using IS, sequentially has influence on behavior intention to use, which is the key factor for determining actual conditions of system use as shown in Fig. 1.

\section{Materials and Methods}

The decision of whether or not to hold out a qualitative or a quantitative approach lies on the researcher's assumptions (Kanaan, 2009; Abu-Dalbouh, 2013). The present study relies quantitative approach and a form is employed for the aim of meeting the objectives of the study. We have a tendency to take for a quantitative because it helps to supply an outline of the trends during a population or an outline of the relationships among its variables (Creswell, 2011; Abu-Dalbouh, 2013).

In addition to the present advantage, a quantitative is additionally cheap to be conducted and it's less time intense because it permits the investigator to amass each 
quantitative scale and qualitative information from an outsized analysis sample. For this reason, a form style as well as measure was utilized within the gift study to look at the variables within the adoption model and to realize analysis of eight queens chess puzzle game system. Moreover, a Likert scale is applied for each set of questionnaires. The likert scale is designed to examine how strongly subjects agree or disagree with statements on a five-point scale with the following anchors: (1) Strongly disagree, (2) Disagree, (3) Nature, (4) Agree, (5) Strongly agree (Chomeya, 2010). In this study the planned methodology was developed in 5 phases. For each section has method step(s) and output for better understanding of what the most goal of each section as illustrated in methodology section (Abu-Dalbouh, 2013).

Sampling Technique: Sampling may be a procedure that entails utilizing a little range of units in a very given population as a basis for drawing conclusions relating to the total population (Jemain et al., 2007). The sample is taken into account as a set of the population comprising of some members designated from it (Al-Omari et al., 2008). We have a tendency to aim to be ready to draw generalized conclusions supported the population underneath study.

Analysis Techniques: There are three main objectives of implementing knowledge analysis: (i) Obtaining summary for the sample knowledge and its attributes, (ii) testing the goodness of knowledge and (iii) supportive the planned hypotheses.

Variable Measurement: The methodology applied within the study is predicated on the questionnaire approach. The target of the questionnaire approach is largely to evaluate the eight queens chess puzzle game system. The form contains 5 sections: Personal information, perceived usefulness, perceived ease of use, user satisfaction and attribute of usability. These sections have variety of queries created to evaluate the effectives of the eight queens chess puzzle game model to the meant users.

\section{Proposed Methodology}

This methodology is developed primarily based upon a mixture of the on the available literature and also the experiences of the author, who are actively involved with the development of using eight queens chess puzzle game system. Figure 2 shows the phases of a planned analysis methodology. The sequence of the phases isn't rigid. Moving back and forth between totally different phases is often needed. It depends on the result of every section that section or that specific output of a section, has got to be performed next. The arrows indicate the most important and frequent dependencies between phases (Abu-Dalbouh, 2013).

\section{Proposed Methodology}

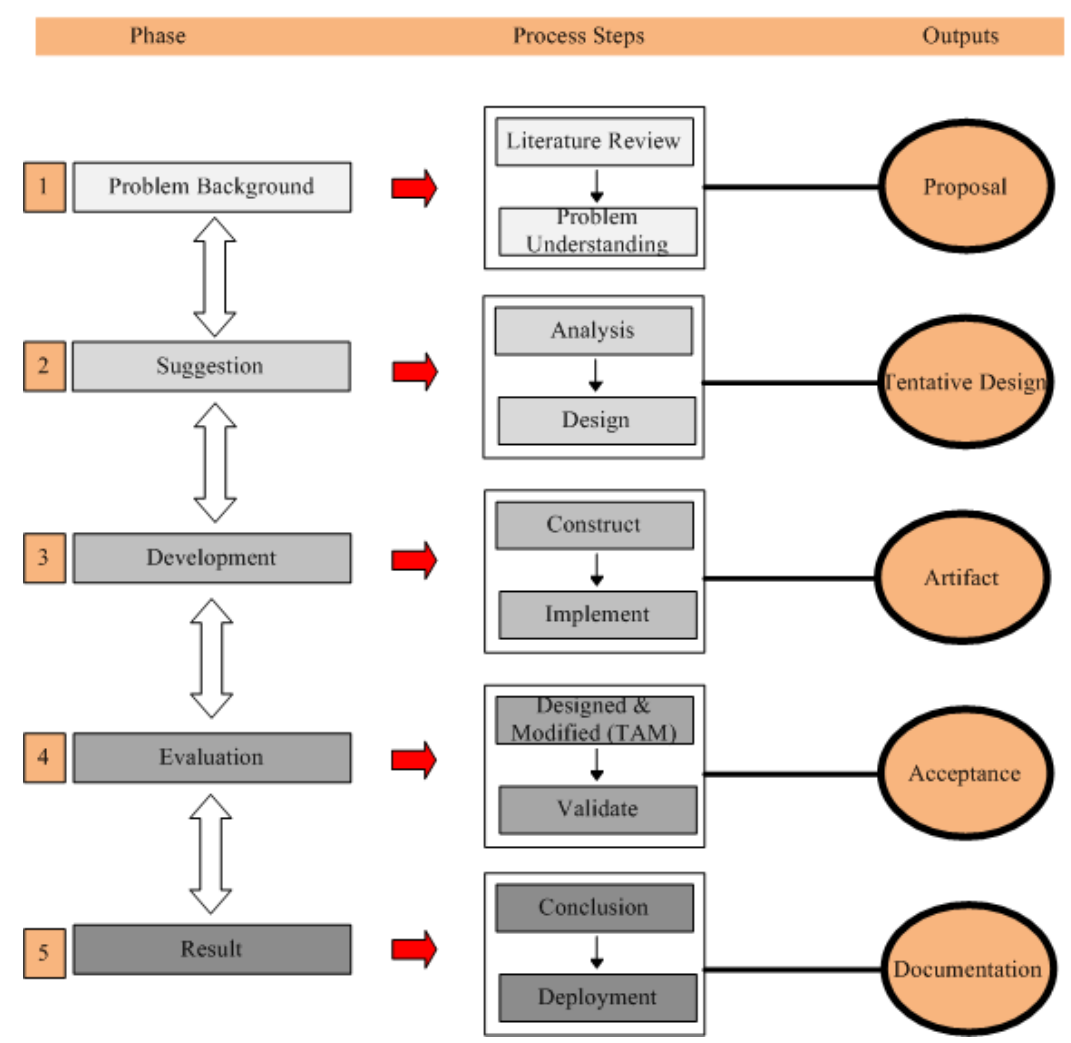

Fig. 2. Proposed methodology (Abu-Dalbouh, 2013) 


\section{Phase 1: Problem Background}

This initial part focuses on understanding the analysis objectives, constraints and limitations from an environment perspective, then changing this information into a problem definition and a preliminary arrange designed to realize the objectives. The output of this part is proposal.

\section{Phase 2: Suggestion}

During this section recommend a tentative style supported the matter definition to attain the objectives of the study. The output of this section is tentative style.

\section{Phase 3: Development}

In this phase the Tentative Design will be developed. The output of this phase is artifact.

\section{Phase 4: Evaluation}

The evaluation was performed to determine the correctness of the eight queens chess puzzle game system model. It utilized a quantitative approach based a Technology Acceptance Model (TAM). The output of this phase is acceptance.

\section{Phase 5: Result}

The output of the last phase is documentation, it is the finale of a specific study effort.

\section{Technology Acceptance Theory}

There are several theoretical views are developed so as to know however finish users build selections to use technology applications. Theories offer tools to know success or failure in implementation processes of recent IT applications. The foremost dominant theories in IT analysis area unit Innovation Diffusion Theory (IDT) (Rogers, 1995), Theory of Planned Behavior (TPB) (Fishbein and Ajzen, 1975), the Unified Theory of Acceptance and Use of Technology (UTAUT) (Venkatesh et al., 2003), the FITT framework (Ammenwerth et al., 2002) and therefore the Technology Acceptance Model (TAM) (Davis, 1989; Davis et al., 1989).

According to (Davis 1989; Davis et al., 1989) Technology Acceptance Model is presumably the foremost oft used among all alternative theories (Ma and Liu, 2004; Kim and Yangtze, 2007; Yarbrough and Smith, 2007). Cap theory is predicated on principles adopted from Fishbein and Ajzen (1975) angle paradigm from psychological science that specifies the way to live the behavior-relevant parts of attitudes, distinguishes between beliefs and attitudes and specifies however external stimuli are causally joined to beliefs, attitudes and behavior. The theoretical model on that cap is predicated is that the Theory of Reasoned Action (TRA).
TRA could be a general model that is bothered with people supposed behaviors. Consistent with TRA AN individual's performance is decided by the individual's angle and subjective norms regarding the behavior in question. Additionally AN individual's beliefs and motivation move with existing behavior (Ajzen and Fishbein, 1980).

The Technology Acceptance Model (TAM) determines the user acceptance of any technology Perceived Usefulness (PU) and Perceived Ease of Use (PEOU) factors. Perceived usefulness defines the degree that a personal believes that employing a specific system can enhance the task performance. Perceived ease of use defines as the degree to that a personal believes that employing a specific system is freed from physical and mental effort (Davis, 1989; Davis et al., 1989; Davis, 1993). The Technology Acceptance Model suggests that intention to simply accept technology is decided directly by attitude. Based on Technology Acceptance Model individuals' intention to use technology determines the particular use of the application and attitudes toward technology have an effect on the intention (Davis et al., 1989; Davis and Venkatesh, 2004).

The various external variables such as level of education (Burton-Jones and Hubona 2005), gender (Venkatesh and Morris, 2000), or organizational features such as training in computer use (Venkatesh, 1999) can be affected Perceived usefulness and perceived ease factors Perceived usefulness and perceived ease factors.

TAM theory is wide utilized in analysis contexts also like many styles of technology applications (Chau and $\mathrm{Hu}, 2001$; Lee et al., 2006; Raitoharju, 2007; Yarbrough and Smith, 2007). It uses for generating explanations for the factors of technology acceptance that are transferable to different kind of user populations and different styles of technologies.

Many different contexts and analysis constructions have conformed the validity of the Technology Acceptance model (Ma and Liu, 2004; King and He, 2006), together with in health care trade (Chau and $\mathrm{Hu}$, 2002a; 2002b; Chismar and Wiley-Patton, 2002).

In this study the TAM is used for the objectives of this study, to structure the research process and to help enhance the understanding of the acceptance and use of proposed eight queens chess puzzle game. Individual factors such as gender and age are external variables. Perceived usefulness is assessed by means of the content and benefits of the incorporating several levels of the eight queens chess puzzle game in order to save time, effort and money from downloading each level separately and the barriers and facilitators to the implementation of the proposed system. The functionality of the application described perceived ease of use of the system. Attitudes toward examined a classic puzzle, how to place eight queens, from $1 \times 1$ to $25 \times 25$ levels, on a chessboard in such a way that no queen can attack any of the others. 


\section{Related Literature in TAM}

The standard code categorizes quality into practicality, Perceived of Perceived Ease of Use, Usefulness, Attribute of Usability and User Satisfaction. This study aims to build of these classes to research the user acceptance of the projected eight queens chess puzzle game system.

From the attitude of Technology Acceptance Model Perceived of Perceived Ease of Use, Usefulness, Attribute of Usability and User Satisfaction are assumed to be connected to the acceptance of a technology or computer system, during this study the acceptance of AN eight queens chess puzzle game system.

Technology Acceptance Model is one among the foremost fashionable theories that's used wide to elucidate data system usage such a big amount of studies are conducted that has semiconductor diode to the changes within the originally suggested model. Taylor and Todd (1995) proposed the combined TAM-TPB model which integrated the theory of planned behavior and TAM. Venkatesh and Davis (2000) suggested a new version of TAM called TAM2 which added new variables to the original TAM model. Venkatesh et al. (2003) in a study published in MIS quarterly proposed the Unified Theory of Acceptance and Use of Technology (UTAUT) Model. There are many studies conducted by authors have attempt to modify the TAM by including new variables to the existing model. In the study by Moon and Kim (2001) are added a new variable playfulness factors to study acceptance of the World Wide Web. Chau (1996) has included two types of perceived usefulness: Long-term and near-term. Van der Heijden (2000) has analyzed the usage of the website and usage individual acceptance by adding two constructs to TAM: Perceived presentation attractiveness and Perceived entertainment value. Furthermore (Abu-Dalbouh et al., 2015) for the purpose to evaluate the institutional and academic performance in College of Sciences and Arts in Unaizah-Qassim University has modified a technology acceptance model. Chau and $\mathrm{Hu}$ (2001) has combined TAM with the factor of peer Influence. Sanchez-Franco and Roldan (2005) have investigate the relationship between behavioral intention and perceived usefulness and conclude that is strong among goal-directed users. Chau and Hu (2001) has compared three models Theory of Planned Behavior (TPB), Technology Acceptance Model (TAM) and a decomposed TPB model that is potentially adequate in the targeted healthcare professional setting in Hong Kong. The study indicated and conclude that TAM was superior to TPB in explaining the physicians' intention to use telemedicine technology. Shih (2004) combined the TAM and the information behavioral model that takes notice of the relevance of the information. Lee (2009) combined the Technology Acceptance Model with Theory of Planned Behavior, perceived risk and perceived benefit to understand the adoption of internet banking. TAM has been used by researchers worldwide to understand the acceptance of different types of information systems. Shafeek (2011) has used the TAM to evaluate the acceptance of e-Learning systems by teachers. Zhou et al. (2007) has proposed a new model called Online Shopping Acceptance Model (OSAM) based on TAM to investigate online shopping behavior. Pavlou (2003) has added trust and perceived risk as new variables to predict the acceptance of e-commerce. Pikkarainen et al. (2004) has developed model to understand the acceptance online banking in Finland, information in online banking and perceived usefulness play a very important role. Hsu and Chiu (2004) suggested a model that specifies that the acceptance pattern and role of internet self-efficacy plays an important role in e-service adoption. Ervasti and Helaakoski (2010) have developed a model based on TAM and TPB to understand mobile service adoption which states that perceived useful is the strongest factor in adoption. Muller-Seitz et al. (2009) used the Technology Acceptance Model with security concern to understand acceptance of Radio Frequency Identification (RFID). Abu-Dalbouh (2013) in the study designed a technology acceptance model to investigate the user acceptance of using a handheld solution in healthcare industry. Abu-Dalbouh (2016) proposed a novel evaluation model to evaluate user acceptance of software and system technology by modifying the dimensions of the Technology Acceptance Model (TAM).

\section{Discussion}

The standard software categorizes quality into functionality, Perceived of Usefulness, Perceived Ease of Use, User Satisfaction and Attribute of Usability. This paper aims to design all these categories to investigate the user acceptance of the proposed eight queens chess puzzle game system. From the perspective of TAM, perceived ease of use, perceived usefulness, user satisfaction and attribute of usability are assumed to be related to the acceptance of a computer or technology system, in this study the acceptance of an eight queens chess puzzle game system.

High levels of user satisfaction are important to eight queens chess puzzle game system. The effects of four components of satisfaction, Perceived of Usefulness Satisfaction and Satisfaction of Perceived Ease of Use, User Satisfaction and Satisfaction of Attribute of Usability on overall satisfaction with players will investigate. It will discuss about effectiveness of the eight queens chess puzzle game from $1 \times 1$ to $25 \times 25$ levels systems. 
Table 2. Perceived of usefulness items

\begin{tabular}{lll}
\hline Construct & Operational definitions & Measured items \\
\hline $\begin{array}{l}\text { Perceived } \\
\text { of usefulness }\end{array}$ & $\begin{array}{l}\text { Perceived usefulness is a feeling that } \\
\text { the proposed eight queens chess puzzle } \\
\text { game serves a particular-aged group to }\end{array}$ & PU1: Eight queens chess puzzle game \\
evaluate their intelligence, learning & PUstem enhances creativity \\
decision-making and the way of thinking. & involves problem solving techniques \\
& PU3: Eight queens chess puzzle game system will \\
In addition, save time, money and effort & improve decision-making and thinking strategies \\
by collecting all levels in a single game & PU4: Eight queens chess puzzle game system allows \\
with series of episodes. & players to test their consistency, skills and strategy \\
& while competing in a more levels \\
& PU5: Eight queens chess puzzle game system is added \\
& more enjoyment and excitement \\
& PU6: Eight queens chess puzzle game system will help \\
& the players by displaying all solutions while playing \\
& PU7: Eight queens chess puzzle game system will save time, \\
& effort and money from downloading each level separately \\
\hline
\end{tabular}

Table 3. Perceived ease of use items

\begin{tabular}{lll}
\hline Construct & Operational definitions & Measured items \\
\hline $\begin{array}{l}\text { Perceived ease } \\
\text { of use }\end{array}$ & $\begin{array}{l}\text { Perceived ease of use refers to a level of } \\
\text { easiness that players feel when using eight } \\
\text { queens chess puzzle game system. }\end{array}$ & $\begin{array}{l}\text { EU1: Learning to operate eight queens chess puzzle game } \\
\text { would be ease for me }\end{array}$ \\
& $\begin{array}{l}\text { EU2: I would find it easy get eight queens chess puzzle } \\
\text { game system to do what I want it to do }\end{array}$ \\
& $\begin{array}{l}\text { EU3: My interaction with eight queens chess puzzle } \\
\text { game system would be clear and understandable }\end{array}$ \\
& $\begin{array}{l}\text { EU4: I would find eight queens chess puzzle game } \\
\text { system to be flexible to interact with }\end{array}$ \\
& EU5: It would be easy for me to become skillful at using \\
& eight queens chess puzzle game system \\
\hline
\end{tabular}

Table 4. User satisfaction items

\begin{tabular}{lll}
\hline Construct & Operational definitions & Measured items \\
\hline User satisfaction & User satisfaction refers to a level of & US1: I completely satisfied in using the eight queens chess \\
& satisfying that players of using eight & puzzle game system \\
& queens chess puzzle game system & US I feel very confident in using the eight queens chess \\
& puzzle game system \\
& US3: I found it easy to display all solutions while playing \\
& the proposed queens challenge game at any level \\
& US4: I can accomplish the task quickly using this procedure \\
& US5: I believe that from using eight queens chess puzzle \\
& game system will add more enjoyment and excitement. \\
\hline
\end{tabular}

Table 5. Attribute of usability items

\begin{tabular}{lll}
\hline Construct & Operational definitions & Measured items \\
\hline attribute of & Attribute of usability shows up & AU1: It easy to interact with eight queens chess puzzle game system \\
usability & potential issues in the eight queens chess & AU2: The procedure through eight queens chess puzzle game is clear \\
& $\begin{array}{l}\text { puzzle game system. The usability helps to } \\
\text { get feedback on what is or is not working }\end{array}$ & AU3: I found it easy to check all the possible solutions for all levels \\
& $\begin{array}{l}\text { and have a much broader understanding } \\
\text { of what players are doing and how they } \\
\text { interact with the system. }\end{array}$ & AU5: I think that I would like to use this game system always \\
&
\end{tabular}

Perceived of Usefulness: It is defined the degree to which a players believes that eight queens chess will be improving by proposed eight queens chess puzzle game from $1 \times 1$ to $25 \times 25$ levels system. The measurement of perceived usefulness comprises of 5 items modified to the context of this study as shown in Table 2.
Perceived Ease of Use: It refers to the degree to which believes that using, designing and collecting all levels in a single game of the proposed eight queens chess puzzle game from $1 \times 1$ to $25 \times 25$ levels in order to save time, effort and money from downloading each level separately. The measurement of perceived ease of 
use construct contained 5 items and modified to the context of this study as shown in Table 3.

User Satisfaction: It are often tough during a form of things and connected to system. It's an extremely personal assessment that's greatly tormented by user expectations. The measurement of user satisfaction construct contained 5 items and modified to the context of this study as shown in Table 4.

Attribute of Usability: It is the world of HumanComputer Interaction (HCI) with eight queens chess puzzle game system. It tries to bridge the gap between human's goals and also the system. This can be being done by introducing the human problems into the look of interactive eight queens chess puzzle game system and by production sensible techniques to look at human behavior and observe their performance. The measurement of attribute of usability construct contained 5 items and modified to the context of this study as shown in Table 5.

\section{Conclusion}

Artificial Intelligence researchers have for decades worked on building game playing systems capable of matching wits with the strongest humans in the world. The success of such systems has largely been because of improved search algorithms and years of relentless knowledge engineering effort on behalf of the program developers, manually adding game specific knowledge to their programs. Therefore the main Artificial Intelligence (AI) is the theory and development of computer systems able to perform tasks normally requiring human intelligence, such as visual perception, speech recognition, decision-making and translation between languages. N-Queens problem is a classic example used in artificial intelligence. This paper introduces a proposed eight queens chess puzzle game from $1 \times 1$ to $25 \times 25$ levels system and designs the Technology Acceptance Model (TAM) for its validation. In fact, there is an eminent need to investigate the collecting all levels in a single game with series of episodes that are tailored towards to serves a particular-aged group to evaluate their intelligence, learning decision-making and the way of thinking. Moreover, incorporating several levels of the Eight Queens Chess Puzzle Game in order to save time, effort and money from downloading each level separately. We proposed methodology designed a Technology Acceptance Model (TAM) approach based on the literature studies aimed to evaluate and investigate usability test for Perceived of Usefulness, Perceived Ease of Use, User Satisfaction and Attribute of Usability as important for the user evaluation in the Eight Queens Chess Puzzle Game system to assess if such this pro-posed game system will be of much use to the intended users.

\section{Acknowledgement}

I would like to thank Qassim University, Kingdom of Saudi Arabia. This study was supported in part by a grant from Deanship of Scientific Research, Qassim University.

\section{Ethics}

This article is original and contains unpublished material. The corresponding author approved the manuscript and confirms that no ethical issues involved.

\section{References}

Abu-Dalbouh, H.M., 2016. An integrated expert user with end user in technology acceptance model for actual evaluation. Comput. Inform. Sci. Canadian Center Sci. Educ., 9: 47-53.

DOI: $10.5539 /$ cis.v9n1\%25p

Abu-Dalbouh, H.M., 2013. A questionnaire approach based on the technology acceptance model for mobile tracking on patient progress applications. J. Comput. Sci., 9: 763-770. DOI: 10.3844/jessp.2013.763.770

Abu-Dalbouh, H.M., E. Al-Roieshdie, A. Al-Otaibi, B. Al-Ma7ana and H. Al-Mutairi et al., 2015. A proposed website to evaluate the academic performance in college of sciences and arts in unaizah. Res. J. Applied Sci. Eng. Technol., 11: 1305-1319. DOI: 10.19026/rjaset.11.2239

Al-Omari, A.I., K. Jaber and A. Al-Omari, 2008. Modified ratio-type estimators of the mean using extreme ranked set sampling. J. Math. Stat., 4: 150-155.

DOI: $10.3844 /$ jmssp.2008.150.155

Ajzen, I. and M. Fishbein, 1980. Understanding Attitudes and Predicting Social Behavior. 1st Edn., Prentice-Hall, Englewood Cliffs, ISBN-10: 0139364439, pp: 278.

Ammenwerth, E., F. Ehlers, U. Kutscha, R. Eichstädter and F. Resch, 2002. Supporting patient care by using innovative information technology: A case study from clinical psychiatry. Disease Manage. Health Outcomes, 10: 479-487.

DOI: $10.2165 / 00115677-200210080-00004$

Burton-Jones, A. and G.S. Hubona, 2005. Individual differences and usage behavior: Revisiting a technology acceptance model assumption. Datab. Adv. Inform. Syst., 36: 58-77.

DOI: $10.1145 / 1066149.1066155$

Chau, P.Y.K., 1996. An empirical assessment of a modified technology acceptance model. J. Manage. Inform. Syst., 13: 185-204. DOI: 10.1080/07421222.1996.11518128

Chau, P. and P. Hu, 2001. Information technology acceptance by individual professionals: A model comparison approach. Decis. Sci., 32: 699-719. DOI: 10.1111/j.1540-5915.2001.tb00978.x 
Chau, P. and P. Hu, 2002a. Investigating healthcare professionals' decisions to accept telemedicine technology: An empirical test of competing theories. Inform. Manage., 39: 297-311. DOI: $10.1016 / \mathrm{S} 0378-7206(01) 00098-2$

Chau, P. and P. Hu, 2002b. Examining a model of information technology acceptance by individual professionals: An exploratory study. J. Manage. Inform. Syst., 18: 297-311.

Chismar, W. and S. Wiley-Patton, 2002. Does the extended technology acceptance model apply to physicians? Proceedings of the 36th Hawaii International Conference on System Sciences, (CSS' 02), pp: 160-167.

Chomeya, R., 2010. Quality of psychology test between likert scale 5 and 6 points. J. Soc. Sci., 6: 399-403. DOI: $10.3844 /$ jssp. 2010.399 .403

Creswell, J.W., 2011. Educational Research: Planning, Conducting and Evaluating Quantitative and Qualitative Research. 4th Edn., Pearson, Boston, ISBN-10: 0131367390, pp: 650.

Davis, F.D., 1989. Perceived usefulness, perceived ease of use and user acceptance of information technology. MIS Q., 13: 319-340. DOI: 10.2307/249008

Davis, F.D., 1993. User acceptance of information technology: system characteristics, user perceptions and behavioral impacts. Int. J. Man-Machine Stud., 38: 475-487. DOI: 10.1006/imms. 1993.1022

Davis, F.D., R.P. Bagozzi and P.R. Warshaw, 1989. User acceptance of computer technology: A comparison of two theoretical models. Manage. Sci., 35: 982-1003. DOI: $10.1287 / \mathrm{mnsc}$.35.8.982

Davis, F.D. and V. Venkatesh, 2004. Toward preprototype user acceptance testing of new information systems: Implications for software project management. Eng. Manage., 51: 31-46. DOI: $10.1109 /$ TEM.2003.822468

Ervasti, M. and H. Helaakoski, 2010. Case study of application-based mobile service acceptance and development in Finland. Int. J. Inform. Technol. Manage., 9: 243-259.

Fishbein, M. and I. Ajzen, 1975. Belief, Attitude, Intention and Behavior: An Introduction to Theory and Research. 1st Edn., Addison-Wesley Pub. Co., Reading, ISBN-10: 0201020890, pp: 578.

Hsu, M.H. and C.M. Chiu, 2004. Internet self-efficacy and electronic service acceptance. Decis. Support Syst., 38: 369-381. DOI: 10.1016/j.dss.2003.08.001

Jemain, A.A., A. Al-Omari and K. Ibrahim, 2007. Multistage median ranked set sampling for estimating the population median. J. Math. Stat., 3: 58-64. DOI: 10.3844 /jmssp.2007.58.64

Moon, J.W. and Y.G. Kim, 2001. Extending the TAM for a World-Wide-Web context. Inform. Manage., 38: 217-230. DOI: 10.1016/S0378-7206(00)00061-6
Kanaan, R., 2009. Making sense of E-government implementation in Jordan: A qualitative investigation. $\mathrm{PhD}$ Thesis, De Montfort University, Leicester.

Kim, D. and H. Chang, 2007. Key functional characteristics in designing and operating health information websites for user satisfaction: An application of the extended technology acceptance model. Int. J. Med. Inform., 76: 790-800. DOI: 10.1016/j.ijmedinf.2006.09.001

King, W.R. and J. He, 2006. A meta-analysis of the technology acceptance model. Inform. Manage., 43: 740-755. DOI: 10.1016/j.im.2006.05.003

Lee, M.C., 2009. Factors influencing the adoption of internet banking: An integration of TAM and TPB with perceived risk and perceived benefit. Electr. Commerce Res. Applic., 8: 130-141. DOI: $10.1016 /$ j.elerap.2008.11.006

Lee, S., I. Kim, S. Rhee and S. Trimi, 2006. The role of exogenous factors in technology acceptance: The case of object-oriented technology. Inform. Manage., 43: 469-480. DOI: 10.1016/j.im.2005.11.004

Ma, Q. and L. Liu, 2004. The technology acceptance model: A meta-analysis of empirical findings. J. Organ. End User Comput., 16: 59-72. DOI: 10.4018/joeuc.2004010104

Muller-Seitz, G., K. Dautzenberg, U. Creusen and C. Stromereder, 2009. Customer acceptance of RFID technology: Evidence from the German electronic retail sector. J. Retail. Consumer Serv., 16: 31-39. DOI: 10.1016/j.jretconser.2008.08.002

Pavlou, P.A., 2003. Consumer acceptance of electronic commerce: Integrating trust and risk with the technology acceptance model. Int. J. Electr. Commerce, 7: 69-103.

Pikkarainen, T., K. Pikkarainen, H. Karijaluoto and S. Pahnila, 2004. Consumer acceptance of online banking: An extension of the technology acceptance model. Internet Res., 14: 224-235. DOI: $10.1108 / 10662240410542652$

Raitoharju, R., 2007. Information technology acceptance in the Finnish social and healthcare sector. Exploring the effects of cultural factors. Publications of the Turku School of Economics.

Rogers, E.M., 1995. Diffusion of Innovations. 1st Edn., Simon and Schuster, ISBN-10: 1451602472, pp: 518.

Sanchez-Franco, M. and J. Roldan, 2005. Web acceptance and usage model: A comparison between goal-directed and experiential web users. Internet Res., 15: 21-48. DOI: 10.1108/10662240510577059

Shafeek, S.A., 2011. E-learning technology acceptance model with cultural factors. MSc. Thesis, Liverpool John Moores University, School of Computing and Mathematical Sciences.

Shih, H.P., 2004. An empirical study on predicting user acceptance of e-shopping on the Web. Inform. Manage., 41: 351-368.

DOI: $10.1016 / \mathrm{S} 0378-7206(03) 00079-\mathrm{X}$ 
Taylor, S. and P.A. Todd, 1995. Assessing IT usage: The role of prior experience. MIS Q., 19: 561-570. DOI: $10.2307 / 249633$

Van der Heijden, H., 2000. Using the technology acceptance model to predict website usage: Extensions and empirical test. Serie Res. Memoranda.

Venkatesh, V., 1999. Creation of favorable user perceptions: Exploring the role of intrinsic motivation. MIS Q., 23: 239-260. DOI: 10.2307/249753

Venkatesh, V. and M.G. Morris, 2000. Why don't men ever stop to ask for directions? Gender, social influence and their role in technology acceptance and usage behavior. MIS Q., 24: 115-139. DOI: 10.2307/3250981

Venkatesh, V. and F.D. David, 2000. A theoretical extension of the technology acceptance model: Four longitudinal field studies. Manage. Sci., 46: 186-204. DOI: $10.1287 / \mathrm{mnsc} .46 .2 .186 .11926$
Venkatesh, V., M.G. Morris, G.B. Davis and F.D. Davis, 2003. User acceptance of information technology: Toward a unified view. MIS Q., 27: 425-478.

Yarbrough, A.K. and T.B. Smith, 2007. Technology acceptance among physicians: A new take on TAM. Medical Care Res. Rev., 64: 650-672. DOI: $10.1177 / 1077558707305942$

Zhou, L., L. Dai and D. Zhang, 2007. Online shopping acceptance model-a critical survey of consumer factors in online shopping. J. Electr. Commerce Res., 8: 41-62. 